\title{
Effect of Stem-Based Activities Conducted in Science Classes on Various Variables
}

\author{
Barış Çayci ${ }^{1}$ \\ Gizem Tabaru Örnek ${ }^{2 \rtimes}$
}

'Assoc. Prof Dr., Department of Primary Education, University of Omer Halisdemir, Turkey

Email:bcavci@ohu.edu.tr.Tel:0532724.5303

${ }^{2}$ Research Assistant, Department of Primary Education, University of Karamanoglu Mehmetbey, Turkey

Email: gizemtabaru@kmu.edu.tr.Tel:05537991091

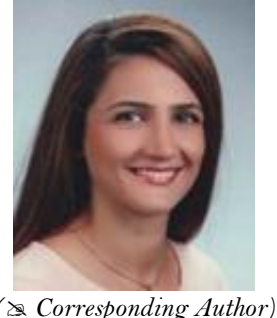

Abstract

The aim of this study was to examine the effect of STEM-based activities conducted in fourth-grade primary school science classes on students' scientific process skills, problem-solving skills and academic success. The study used the experimental model and was carried out according to the pretest-posttest experimental design with a control group. The study group of the research was made up of fourth-grade students at a primary school in the centre of Karaman province. The "Basic Skills Scale", "Problem-Solving Skills Scale" and "Test of Academic Success" were used as data collection tools. Another finding of the study was that the posttest academic success test scores of the students in the experimental group were significantly higher than those of the students in the control group. This finding reveals that the implementation of a STEM-based activity on the subject of simple electrical circuits was effective on academic success $(U=109.000 \mathrm{p}<.01)$. Following the instruction carried out on the experimental and control groups, there was no significant difference in the mean posttest Basic Skills Scale scores of students in the experimental group on which the STEM-based activities were applied. Moreover, it was determined that the mean posttest ProblemSolving Skills scores of students in the experimental and control groups participating in the study did not show a significant difference $(U=201.500 \mathrm{p}>.05)$. This finding reveals that the STEM-based activities did not have a significant effect on basic process skills or problem-solving skills.

Keywords: Science lessons, STEM, Scientific process skills, Problem solving skills, Academic success

Citation | Barış Çaycı; Gizem Tabaru Örnek (2019). Effect of StemBased Activities Conducted in Science Classes on Various Variables. Asian Journal of Education and Training, 5(1): 260-268. History:

Received: 2 January 2019

Revised: 4 February 2019

Accepted: 7 March 2019

Published: 15 March 2019

Licensed: This work is licensed under a Creative Commons

Attribution 3.0 License (oc)

Publisher: Asian Online Journal Publishing Group
Contribution/Acknowledgement: This study was generated out of Gizem TABARU ORNEK's Master's Thesis conducted under the supervision of Assoc. Prof. Dr. Barıs CAYCI and was presented as an oral statement at the 17th International Classroom Teaching Education Symposium (11th-14th April 2018, Gazi University, Ankara).

Funding: This study received no specific financial support

Competing Interests: The authors declare that they have no conflict of interests.

Transparency: The authors confirm that the manuscript is an honest, Trcurate, and transparent account of the study was reported; that ho study as planned have been explained.

Ethical: This study follows all ethical practices during writing.

\section{Contents}

1. Introduction

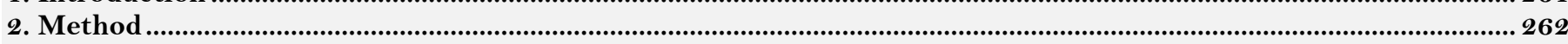

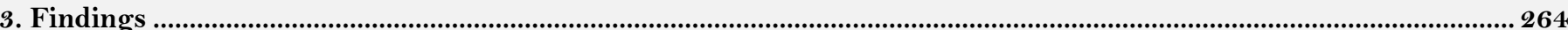

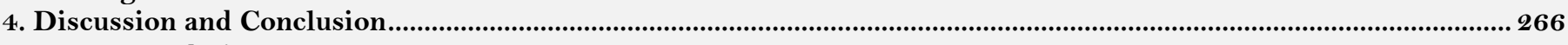

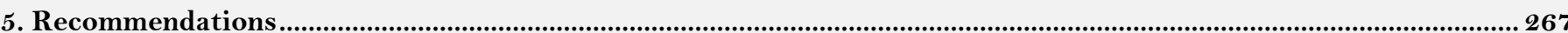

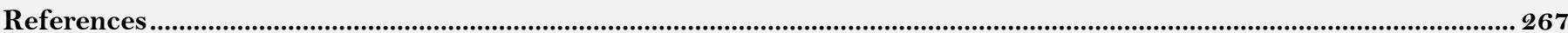




\section{Introduction}

In parallel with the advances in science and technology, the changes that occur in branches of science also have a deep impact on every area of human life. The acceleration in this race for development in the world has made it necessary for countries to make changes to their education policies. Nations have made different plans for improving the quality of their education and have revised and reintroduced their education programmes.

In the modern age, when scientific knowledge is growing and developing, technological innovations are rapidly advancing, and science and technology affect every area of our lives, the importance given to the sciences for societies to attain better futures is increasing (Ministry of Education, 2013). In parallel with the innovations in education in the world, the education programmes in our country are being revised and renewed. The aims of the 2018 Science Lesson Teaching Programme are to bring solutions to problems encountered in everyday life, and to use scientific process skills and life skills for the discovery of nature and for better understanding of the humanenvironment relationship (MoE, 2018). Padilla (1990) defined scientific process skills as skills suited to several scientific disciplines that reflect the behaviours of scientists and can generally be transferred from one to another. Ostlund (1992) defined scientific process skills as the most powerful tool used for obtaining information related to everything in an individual's environment and for organising this gathered information. Cepni et al. (1997) defined skills that facilitate the learning of science, that bring about ways and methods of doing research, that activate, that increase responsibility for one's own learning and that enable retention of learning as scientific process skills. In the most general definition, scientific process skills are thinking skills that aim at thinking about problems, creating knowledge and, by combining these, reaching a conclusion. These skills are a basic step taken to access information, and scientists also use these skills in their research (Caycı and Kılıç, 2017). The basic aim of education is to raise individuals who can remain standing in the face of life. Daily life is full of complex problems. When considered from this perspective, education is in fact the entire problem-solving process (Serin, 2004). Every person encounters various problems in daily life. While making individuals' lives easier on the one hand, rapidly developing and changing technology also makes problems encountered in daily life more difficult on the other. The relationship between the skills that individuals possess for solving problems and their life quality reveals how important problem-solving skills are. Individuals who possess problem-solving skills adapt more easily to their environment (Senemoğlu, 2009).

In the EU's 2007 report named "Science Education Now: A Renewed Pedagogy for the Future of Europe", it was emphasised that all over Europe, the importance of science and technology education had increased and that young people in particular needed to be directed towards the subjects of science, technology, engineering and mathematics. In the report, frequent reference was made to the use of an inquiry-based science approach in the science education process, and to 21 st-century skills aimed at increasing students' interest in science such as creativity, critical thinking, collaborative study and problem solving (Rocard et al., 2007).

The important place occupied by the sciences in nations' scientific and technological development has also made STEM education important. In a world in which science and technology are advancing at an unstoppable rate, the aim of STEM education is to enable the search for information needed by individuals, access of information by using scientific research methods and the acquisition of skills for using the accessed information in everyday life (Yıldırım, 2016). By integrating the disciplines of science, technology, engineering and mathematics into the teaching-learning process all together, STEM education, which goes by the name of FeTeMM in Turkey, gives students the opportunity to perceive knowledge related to the world they live in as a whole, rather than learning them separately (Cepni et al., 2016) cited from Dugger, 2010). According to Corlu (2012) STEM education is the set of knowledge, skills and beliefs occurring with the intersection of more than one STEM discipline, and each STEM discipline has different individual characteristics. Although STEM is regarded only as mathematics and science disciplines by individuals, the products of technology and engineering also have very great effects on facilitating daily life (Bybee, 2010). In points where two or more STEM subjects intersect, STEM education includes information, skills and beliefs created by cooperation (Corlu et al., 2014). Although STEM is defined in different ways in Turkey and in the world, the common feature of all is its application to a problem in daily life by the integration of concepts and skills in different disciplines. STEM education supports countries' social and economic development and increases their competitive power (Cakmakçı, 2016). The main aim of STEM education is to create an integrated, interdisciplinary approach by forming connections between the disciplines of science, technology, engineering and mathematics (Smith, 2000).

In our rapidly developing and changing world, transformations occurring in every field also affect the characteristics of the qualified labour force. To raise individuals equipped with 21 st-century skills, it is also necessary to prepare teaching programmes that meet the needs of the age. It is not possible to enable the acquisition of these qualities only with science education that includes basic concepts. While students are acquiring these skills, it will be more beneficial to adopt an educational understanding in which four fields are combined, that is, the basic principles of the sciences, the numbers and calculations of mathematics, the use of technology as a tool and the solutions and products revealed by engineering.

In this context, the basic aim of the present study is to examine the effect of STEM-based activities implemented in fourth-grade primary science classes on students' scientific process skills, problem-solving skills and academic success. In line with this aim, answers were sought to the following questions:

I. Is there a significant difference in pretest scores for basic process skills, problem-solving skills and academic success between students in the experimental and control groups?

II. Is there a significant difference between pretest and posttest scores for basic process skills, problem-solving skills and academic success in students in the experimental group?

III. Is there a significant difference between pretest and posttest scores for basic process skills, problem-solving skills and academic success in students in the control group?

IV. Is there a significant difference in posttest scores for basic process skills, problem-solving skills and academic success between students in the experimental and control groups? 


\section{Method}

\subsection{Research Model}

The research uses the experimental model. The experimental model is a research model in which the data one wishes to observe are generated under the direct control of the researcher with the aim of determining cause-andeffect relationships. Whereas in the scanning model, the existing situation is observed, in the experimental model, the data one wishes to observe are developed by the researcher. In a study in the experimental model, the aims are generally stated in the form of a hypothesis. Therefore, the events are tested with their causes (Karasar, 2015). In this study, in which it was aimed to measure the effect of STEM-based activities, applied in the subject of "Simple Electrical Circuits" to fourth-grade primary students in their science lessons, on their scientific process skills, problem-solving skills and academic success, the pretest-posttest with control group model of experimental design was taken as the basis.

In the pretest-posttest with control group model, the groups are created with the random method. One of these groups is assigned as the experimental group, while the other is appointed as the control group. Measurements are taken for both groups prior to and following the implementation. In this model, the existence of a pretest is important for determining the equivalences of the groups prior to the measurement and for comparing the posttest results with these (Karasar, 2015). The symbolic view of the model is summarised in Table 1.

Table-1. Symbolic View of Experimental Design of Study.

\begin{tabular}{l|c|c|c|c}
\hline Group & & PRETEST & OPERATION & POSTTEST \\
\hline Experimental Group & $\mathrm{R}$ & $\mathrm{T} 1-\mathrm{T} 2-\mathrm{T} 3$ & $\mathrm{X}$ & $\mathrm{T} 1-\mathrm{T} 2-\mathrm{T} 3$ \\
\hline Control Group & $\mathrm{R}$ & $\mathrm{T}$ 1-T2-T3 & $\mathrm{Y}$ & $\mathrm{T} 1-\mathrm{T} 2-\mathrm{T} 3$ \\
\hline R: Neutrality in creation of groups. & & \\
T1: Basic Skills Scale. & & \\
T2: Problem-Solving Skills Scale. & & \\
T3: Test of Academic Success. \\
X: Operation carried out (STEM-based activities). \\
Y: Activities suited to 2013 Science Curriculum.
\end{tabular}

\subsection{Study Group}

The study was conducted during the spring term of the 2016-2017 academic year in a primary school in the centre of Karaman province, with permission obtained from Karaman Provincial Directorate for National Education. Based on the willingness of the school principal and teachers from among three different specified schools to participate voluntarily in the research, the study group of the research was chosen.

To determine the experimental and control groups of the research, with the aim of choosing the experimental and control groups equally from among the five fourth-grade classes at the primary school where the research was to be conducted, the "Attitude Scale for the Science and Technology Course" developed by Nuhoğlu (2008) and the "Test of Academic Success in Science" prepared by the researcher, and consisting of the units, "Let's Solve the Mystery of our Bodies", "The Effects of Force" and "Let's Learn about Matter", studied by students up to 21.04.17, were applied. Following these implementations, the gathered data were analysed, and to test the position of the students' mean scores in the test of academic success in science and the attitude scale for science and technology lessons according to the classes, the Kruskal-Wallis H Test was performed. The differences in students' mean scores in the "Test of Success in Science" $\left(\mathrm{x}^{2}=35.623 ; \mathrm{sd}=4 ; \mathrm{p}<.05\right)$ and in the "Attitudes towards Science and Technology Lessons" $\left(\mathrm{x}^{2}=10.694 ; \mathrm{sd}=4 ; \mathrm{p}<.05\right)$ and "Attitudes towards Activities in Science and Technology Lessons" subdimensions of the "Attitude Scale for the Science and Technology Course" were found to be statistically significant according to the class that they studied in $(\mathrm{p}<.05)$. To determine between which groups there were significant differences, the Mann-Whitney U Test was performed. When the scores obtained from the test of academic success in science and the attitude scale for science and technology lessons were compared, it was determined that D-F, D-E and C-F classes were equal. These findings support the first subproblem of the research.

From these three equal pairs of classes, it was decided to randomly select classes D and $\mathrm{F}$ as the study group of the research. It was determined that academic success in science and attitudes towards science of students in these classes chosen for the study group were at the same levels. Moreover, when the total number of students in the other classes and the number of boys and girls in each class were compared, it was found that the total number of students and the distribution of boys and girls in classes D and F chosen for the study group of the research were close to each other.

Following these studies, one of the two classes chosen was assigned as the experimental group, while the other class was designated as the control group by the random method. In the experimental and control groups of the study, lessons suited to the determined teaching method were given over a period of three weeks for a total of 12 lesson periods. The lessons for the experimental group were conducted by the researcher with the implementation of STEM-based activities, while the students in the control group were taught by their classroom teachers with teaching methods prepared according to the 2013 science curriculum.

\subsection{Preparation of Teaching Materials and Teaching Process}

The unit for which the implementation was to be carried out was determined as the "Simple Electrical Circuits" unit of the fourth-grade science course. This unit was chosen because the STEM-based activities to be implemented were more suited to the selected unit. In the implementation process, the science lessons were applied by the researcher to the experimental group with STEM-based activities and the $7 \mathrm{E}$ model. The $7 \mathrm{E}$ model was used in the lessons with the experimental group and at the end of every week, an outcome was determined. The $7 \mathrm{E}$ model has several positive effects on students, such as correcting misconceptions, enabling retention of learning, relying more on experimental activities, encouraging individuals to do research, active use of scientific process skills and developing problem-solving skills. Moreover, since the $7 \mathrm{E}$ model conforms to the basic structure of the STEM approach, it was used in the implementation as the teaching method. The teaching of the same subject to the control group was undertaken by the class teacher based on the 2013 curriculum for the science course. The 
relevant unit is comprised of three learning outcomes and was carried out over a period of 12 lesson periods, as stated in the curriculum. The activities for the experimental and control groups over the five-week implementation period are included in Table 2 .

Table-2. Implementation process of study.

\begin{tabular}{l|l|l}
\hline Week & Experimental Group Activities & Control Group Activities \\
\hline 1st Week & Pretest (BSS, PSSS, TAS) and introduction & Pretest (BSS, PSSS, TAS) and introduction \\
\hline 2nd Week & I can set up an electrical circuit & Activities conforming to 2013 Science Curriculum \\
\hline 3rd Week & Vibrating robot & Activities conforming to 2013 Science Curriculum \\
\hline 4th Week & I can make a car & Activities conforming to 2013 Science Curriculum \\
\hline 5th Week & Posttest (BSS, PSSS, TAS) and final meeting & Posttest (BSS, PSSS, TAS) and final meeting \\
\hline BSS=Basic Skills Scale; PSSS=Problem-Solving Skills Scale; TAS=Test of Academic Success.
\end{tabular}

\subsection{Data Collection Tools}

In this study, a total of three measurement tools, namely the "Basic Skills Scale", "Problem-Solving Skills Scale" and "Test of Academic Success", were used as data collection tools.

\subsubsection{Basic Skills Scale}

In the study, in order to measure the fourth-grade primary students' skills in the basic scientific process, the Basic Skills Scale developed by Padilla et al. (1985) adapted into Turkish by Aydoğdu and Karakuş (2015) was used. Permission to use the Basic Skills Scale was obtained via email.

This test is in the form of a multiple choice test consisting of 31 items. The basic skills scale measures 6 basic process skills, namely observation, classification, inference, prediction, measurement and communication, and the validity and reliability study was repeated by the researcher and conducted with 103 students in a school independent of the school where the implementation was to be carried out.

For the validity study of the basic skills scale, expert opinion was sought and the Lawshe method was used. According to Lawshe (1975) content validity ratios are obtained by gathering the views of experts for each item. The content validity ratio (CVR) is obtained by subtracting 1 from the ratio of the number of experts who consider an item "Essential" to half the total number of experts who express an opinion regarding that item. The CVR was obtained for every item in the basic skills scale. When the opinions of a total of six experts were assessed, the CVR was found to be within acceptable limits $(\mathrm{CVR}=0.99)$. The content validity of the scale was thus statistically established.

For the construct validity and reliability of the basic skills scale, the data were analysed with ITEMAN analysis software. While deciding whether to remove an item in the 31-item basic skills scale from the test or to leave it in, both the strength values and the discrimination values were assessed by examining them together (Tan, 2011). The reliability coefficient of the basic skills scale was found as .72, while total discrimination and total strength were determined as .51 and .72 respectively. Following the analyses conducted, 6 items having unacceptable item strength and discrimination values were removed from the 31 -item test. The basic skills scale took its final shape with 25 questions and was ready for implementation.

\subsubsection{Problem-Solving Skills Scale}

To measure the problem-solving skills of the fourth-grade primary students in the study, the "Problem-Solving Skills Scale" developed by Ge (2001) and adapted into Turkish by Coşkun (2000) was used. Permission to implement the scale was obtained via email. The problem-solving skills scale consists of four problem steps and five sentences are included as possible answers to each question. The scale therefore contains a total of 20 sentences in the four problem steps and is a 5-point Likert-type scale.

The validity and reliability study of the problem-solving skills scale was conducted with 103 students in a school independent of the school where the implementation was to be carried out. For the validity study of the scale, expert opinion was sought and the Lawshe method was used. According to Lawshe (1975) content validity ratios are obtained by gathering the views of experts for each item. The content validity ratio (CVR) is obtained by subtracting 1 from the ratio of the number of experts who consider an item "Essential" to half the total number of experts who express an opinion regarding that item. The CVR was obtained for every item in the problem-solving skills scale. When the opinions of a total of six experts were assessed, the CVR was found to be within acceptable limits $(\mathrm{CVR}=0.99)$. The content validity of the scale was thus statistically established.

The construct validity of the problem-solving skills scale was examined using factor analysis. To test the suitability for factor analysis, Bartlett's test and the Kaiser-Mayer-Olkin (KMO) measure were used. Bartlett's test reveals the relationships among the data. The Bartlett Test Statistic was calculated as 898.390; $\mathrm{p}=.000$. The Kaiser-Mayer-Olkin (KMO) test examines the suitability of the sample size for factor analysis. The KMO value was calculated as .831. In social science studies, a KMO value of over .60 generally indicates that the sample size is adequate (Büyüköztürk, 2014). According to the statistical results, it was determined that the data were suitable for a factor analysis study.

Following the factor analysis performed on the scale, five factors of the scale with eigenvalues greater than 1.00 were determined. To decide on the number of factors in the scale, the scree plot indicating the change in eigenvalues was examined. In the graph, it was seen that after the first factor there were very small changes in the line and that their contributions to the variance were close to each other. According to Lord (1980) if the items in the first factor have high loading values, and if, while the eigenvalue and explained variance of the first factor are high, these values are lower in the second factor, and if, however, there is closeness between the eigenvalue of the second factor and that of the next factor, this indicates unidimensionality. Accordingly, the number of factors according to the eigenvalue criterion was determined to be one (Cited from Cokluk et al. (2016)).

As in the original form of the scale, it was determined that the 20 items in the problem-solving skills scale were grouped into one single factor. The ratio of one factor in explaining variance related to the scale was $32.50 \%$. 
Considering that an acceptable ratio is regarded as 30\% (Cokluk et al., 2016) the obtained results reveal that the scale has one factor. For this reason, no items were removed from the scale, and the scale was determined to consist of 20 items and one factor.

\subsubsection{Test of Academic Success}

The test of academic success consists of 20 questions with four choices for each, and was used to measure the academic success of students in the fourth-grade simple electrical circuits unit. Three learning outcomes are included in the subject of simple electrical circuits and five questions were prepared for each outcome. Furthermore, five questions related to the use and safety of electrical tools in everyday life were prepared and added to the test. The validity and reliability study of the test of academic success consisting of the prepared questions was conducted with 103 students in a school independent of the school where the implementation was to be carried out. For the content validity of the academic success test, expert opinion was sought. For the construct validity and reliability of the basic skills scale, the data were analysed with ITEMAN analysis software.

To ensure the content validity of the academic skills test and to test whether it was suitable for the population to be assessed and met characteristics like understandability of the items, expert opinion was sought and the Lawshe method was used. According to Lawshe (1975) content validity ratios are obtained by gathering the views of experts for each item. The content validity ratio (CVR) is obtained by subtracting 1 from the ratio of the number of experts who consider an item "Essential" to half the total number of experts who express an opinion regarding that item. The CVR was obtained for every question in the academic skills test. When the opinions of a total of six experts were assessed, the CVR was found to be within acceptable limits $(\mathrm{CVR}=0.99)$. The content validity of the scale was thus statistically established.

To ensure the reliability of the test, the item strength and item discrimination values were calculated. The strength value of an item closely affects other characteristics of that item like its discrimination value. Therefore, while deciding whether to remove an item from the test or to leave it in, both the strength value and the discrimination value of the item must be assessed by examining them together (Tan, 2011).

Following the analyses performed, one item that did not conform to the item discrimination and strength values was removed from the test made up of 20 questions and item analysis was performed again. The reliability (KR-20) of the developed test of academic skills was calculated as .75, while total discrimination and total strength were calculated as .55 and .57 respectively. Consequently, following the validity and reliability studies performed on the 20-question test of academic success prepared by the researcher on the subject of simple electrical circuits, the test took its final shape with 19 questions and was ready for implementation.

\subsection{Analysis of the Data}

The data gathered in the study were analysed using the SPSS (Statistical Package for Social Sciences) 15 statistical software package. When the number of observations in groups is over 30, statistically stronger results can be obtained. However, when the hypotheses are confirmed, the number of observations can also be applied in cases where it is lower. If population distributions are not normal and the number of observations is less than 30, it will be more suitable to apply nonparametric tests (Alpar, 2014). The Shapiro-Wilk test was used to determine whether the data were normally distributed or not, and the results are given below in Table 3.

Table-3. Shapiro-Wilk test results for distribution of data obtained from experimental and control groups in pretests.

\begin{tabular}{|c|c|c|c|c|c|}
\hline \multicolumn{3}{|l|}{ Group } & \multicolumn{3}{|c|}{ Shapiro-Wilk } \\
\hline & & & \multirow{2}{*}{$\frac{\text { Statistic }}{.870}$} & \multirow{2}{*}{$\frac{\mathbf{n}}{21}$} & \multirow{2}{*}{$\frac{\mathbf{p}}{.009^{*}}$} \\
\hline Basic Skills Scale & Pretest & Experimental & & & \\
\hline & & Control & .929 & 22 & .117 \\
\hline \multirow[t]{2}{*}{ Problem-Solving Skills Scale } & \multirow[t]{2}{*}{ Pretest } & Experimental & .964 & 21 & .602 \\
\hline & & Control & .959 & 22 & .470 \\
\hline \multirow[t]{2}{*}{ Test of Academic Success } & \multirow[t]{2}{*}{ Pretest } & Experimental & .837 & 21 & $.003^{*}$ \\
\hline & & Control & .847 & 22 & $.003^{*}$ \\
\hline
\end{tabular}

$\mathrm{p}<.05^{*}$

In Table 3 related to the distribution of pretest data for students in the experimental and control groups, the results of the Shapiro-Wilk test performed reveal that the pretest for the experimental group in the basic skills test, and the pretestt for the experimental and control group in the test of academic success did not show normal distribution. Moreover, since the number of observations in the groups were less than 30 (Alpar, 2014; Baykul and Güzeller, 2014) nonparametric tests were conducted.

Accordingly, for the first and fourth subproblems of the study, the Mann-Whitney U Test was performed, while for the second and third subproblems, the Wilcoxon Signed Ranks test was applied.

\section{Findings}

\subsection{Findings Related to the First Subproblem}

The first subproblem of the study was defined as "Is there a significant difference in pretest scores for basic process skills, problem-solving skills and academic success between students in the experimental and control groups?" The values obtained from the analyses of the data related to this problem are explained below.

According to the results of the Mann-Whitney U test performed to test the equivalence of the mean pretest scores of the students in the experimental and control groups, no significant difference was found in pretest mean scores in the basic skills scale $(\mathrm{U}=228.00, \mathrm{p}>.05)$, problem-solving skills scale $(\mathrm{U}=220.000, \mathrm{p}>.05)$ or test of academic success $(\mathrm{U}=183.00, \mathrm{p}>.05)$.

Accordingly, it was determined that there were no significant differences in basic skill levels, problem-solving skills or academic success between students between the experimental and control groups, and that the levels of 
basic skills, problem-solving skills and academic success in students in the experimental and control groups were therefore equal.

\subsection{Findings Related to the Second Subproblem}

The second subproblem of the study was defined as "Is there a significant difference between pretest and posttest scores for basic process skills, problem-solving skills and academic success in students in the experimental group?” The results of the Wilcoxon Signed Ranks test performed on the mean pretest and posttest scores of the students in the experimental group for the basic skills scale, problem-solving skills scale and test of academic success are presented below in Table 4.

Table-4. Wilcoxon Signed Ranks test results for mean pretest and posttest scores of experimental group for basic skills scale, problemsolving skills scale and test of academic success.

\begin{tabular}{|c|c|c|c|c|c|c|}
\hline & Pretest- Posttest & $n$ & Mean Rank & Rank Total & $Z$ & $p$ \\
\hline \multirow[t]{3}{*}{ Basic Skills Scale } & Negative Rank & $\mathrm{O}$ & .00 & .00 & 3.95 & $\mathrm{OOO}^{\text {****** }}$ \\
\hline & Positive Rank & 20 & 10.50 & 210.00 & & \\
\hline & Equal & 1 & & & & \\
\hline \multirow[t]{3}{*}{ Problem-Solving Skills Scale } & Negative Rank & 8 & 11.00 & 88.00 & .64 & .525 \\
\hline & Positive Rank & 12 & 10.17 & 122.00 & & \\
\hline & Equal & 1 & & & & \\
\hline \multirow[t]{3}{*}{ Test of Academic Success } & Negative Rank & $\mathrm{O}$ & .00 & .00 & 4.035 & $.000^{* * * *}$ \\
\hline & Positive Rank & 21 & 11.00 & 231.00 & & \\
\hline & Equal & $\mathrm{O}$ & & & & \\
\hline
\end{tabular}

a: based on negative ranks ${ }^{* * *} \mathrm{p}<.001 \mathrm{p}>.05$.

Examining Table 4, it is seen that a significant difference was found between mean pretest and posttest scores for the "Basic Skills Scale" of students in the experimental group $(\mathrm{z}=-3.951, \mathrm{p}<.001)$. Considering the mean ranks and rank totals of the difference scores, it is seen that this observed difference is in favour of the posttest scores. Accordingly, it was determined that the mean posttest scores in the basic skills scale of 20 of the students in the experimental group increased significantly in relation to their mean pretest scores, while there was no difference between the pretest and posttest mean scores of 1 student. Examining the results obtained, it is seen that the STEM-based activity programme had a positive effect on the students' basic skill levels.

No significant difference was found between the mean pretest and posttest scores of the students in the experimental group for the "Problem-Solving Skills Scale" $(\mathrm{z}=.636, \mathrm{p}>.05)$. Accordingly, it was determined that the mean posttest scores in the problem-solving skills scale of 8 of the students in the experimental group decreased significantly in relation to their mean pretest scores, that the mean posttest scores of 12 students increased significantly in relation to their mean pretest scores, and that there was no difference between the mean pretest and posttest scores of 1 student. Examining the results obtained, it is seen that the STEM-based activity programme had no effect on the students' problem-solving skill levels.

Examining Table 4, it is seen that a significant difference was found between mean scores for the "Test of Academic Success" obtained by the students in the experimental group prior to and following the implementation $(\mathrm{z}=-4.035, \mathrm{p}<.001)$. Considering the mean ranks and rank totals of the difference scores, it is seen that this observed difference is in favour of the posttest scores. Accordingly, it was determined that the mean posttest scores of all the students in the experimental group in the test of academic success, which tested their knowledge levels related to simple electrical circuits, increased significantly in relation to their mean pretest scores. Examining the results obtained, it is seen that the STEM-based activity programme had a positive effect on the students' knowledge levels related to simple electrical circuits.

\subsection{Findings Related to the Third Subproblem}

The third subproblem of the study was defined as "Is there a significant difference between pretest and posttest scores for basic process skills, problem-solving skills and academic success in students in the control group?" The results of the Wilcoxon Signed Ranks test performed on the mean pretest and posttest scores of the students in the control group for the basic skills scale, problem-solving skills scale and test of academic success are presented below in Table 5 .

Table-5. Wilcoxon Signed Ranks test results for mean pretest and posttest scores of control group for basic skills scale, problem-solving skills scale and test of academic success.

\begin{tabular}{|c|c|c|c|c|c|c|}
\hline & Pretest- Posttest & $n$ & Mean Rank & Rank Total & $Z$ & $p$ \\
\hline \multirow[t]{3}{*}{ Basic Skills Scale } & Negative Rank & $\mathrm{O}$ & .00 & .00 & 3.77 & $.000^{* * * *}$ \\
\hline & Positive Rank & 18 & 9.50 & 171.00 & & \\
\hline & Equal & 4 & & & & \\
\hline \multirow[t]{3}{*}{ Problem-Solving Skills Scale } & Negative Rank & 7 & 11.79 & 82.50 & .50 & .614 \\
\hline & Positive Rank & 12 & 8.96 & 107.50 & & \\
\hline & Equal & 3 & & & & \\
\hline \multirow[t]{3}{*}{ Test of Academic Success } & Negative Rank & 3 & 7.67 & 23.00 & 2.15 & $.032^{*}$ \\
\hline & Positive Rank & 12 & 8.08 & 97.00 & & \\
\hline & Equal & 7 & & & & \\
\hline
\end{tabular}

a: based on negative ranks ${ }^{* * *} \mathrm{p}<.001 \mathrm{p}>.05 * \mathrm{p}<.05$

Examining Table 5, a significant difference was found between the mean scores for the "Basic Skills Scale" obtained by students in the control group prior to and following the implementation $(\mathrm{z}=-3.768, \mathrm{p}<.001)$. Considering the mean ranks and rank totals of the difference scores, it is seen that this observed difference is in favour of the posttest scores. Accordingly, it was determined that the mean posttest scores in the basic skills scale 
of 18 of the students in the control group increased significantly in relation to their mean pretest scores, while there was no difference between the pretest and posttest mean scores of 4 students.

No significant difference was found between the mean scores obtained by the students in the control group for the "Problem-Solving Skills Scale" prior to and following the implementation $(\mathrm{z}=.50$, $\mathrm{p}>.05)$. Accordingly, it was determined that the mean posttest scores in the problem-solving skills scale of 7 of the students in the experimental group decreased significantly in relation to their mean pretest scores, that the mean posttest scores of 12 students increased significantly in relation to their mean pretest scores, and that there was no difference between the mean pretest and posttest scores of 3 students.

A significant difference was found between mean scores for the "Test of Academic Success" obtained by the students in the control group before and after the implementation $(z=-2.15, p<.05)$. Considering the mean ranks and rank totals of the difference scores, it is seen that this observed difference is in favour of the posttest scores. Accordingly, it was determined that the mean posttest scores of 3 of the students in the control group decreased significantly in relation to their pretest scores for the test of academic success, which tested their knowledge levels related to simple electrical circuits, that the mean posttest scores of 12 of the students increased significantly in relation to their pretest scores, and that there was no difference between the pretest and posttest scores of 7 of the students.

\subsection{Findings Related to the Fourth Subproblem}

The fourth subproblem of the study was defined as "Is there a significant difference in posttest scores for basic process skills, problem-solving skills and academic success between students in the experimental and control groups?" The results of the Mann-Whitney U test performed on the mean posttest scores of the students in the experimental and control groups of the study for the basic skills scale, problem-solving skills scale and test of academic success are presented below in Table 6.

Table-6. Mann-Whitney U test results related to mean posttest scores of students in experimental and control groups in basic skills scale, problem-solving skills scale and test of academic success.

\begin{tabular}{|c|c|c|c|c|c|c|}
\hline & Group & $n$ & Mean Rank & Rank Total & $U$ & $p$ \\
\hline \multirow[t]{2}{*}{ Basic Skills Scale } & Experimental & 21 & 23.31 & 489.50 & 203.500 & .500 \\
\hline & Control & 22 & 20.75 & 456.50 & & \\
\hline \multirow[t]{2}{*}{ Problem-Solving Skills Scale } & Experimental & 21 & 23.40 & 491.50 & 201.500 & .473 \\
\hline & Control & 22 & 20.66 & 454.50 & & \\
\hline \multirow[t]{2}{*}{ Test of Academic Success } & Experimental & 21 & 27.81 & 584.00 & 109.00 & $.002^{*}$ \\
\hline & Control & 22 & 16.45 & 362.00 & & \\
\hline
\end{tabular}

$\mathrm{p}>.05$ * $\mathrm{p}<.01$.

Examining Table 6, no significant difference was found between mean posttest scores of students in the experimental and control groups participating in the study with regard to the "Basic Skills Scale" (U=203.500 $\mathrm{p}>.05)$. While the posttest mean rank score for the basic skills scale of the students in the experimental group was 23.31, the posttest mean rank score of the students in the control group was 20.75. Accordingly, it was determined that the basic skill levels of the students in the experimental and control groups did not differ.

No significant difference was found between mean posttest scores of students in the experimental and control groups participating in the study with regard to the "Problem-Solving Skills Scale" (U=201.500 p>.05). According to Table 6, while the posttest mean rank score for the problem-solving skills scale of the students in the experimental group was 23.40 , the posttest mean rank score of the students in the control group was 20.66 . It was determined that the problem-solving skill levels of the students in the experimental and control groups did not differ.

A significant difference was found between the mean posttest scores of students in the experimental and control groups of the study for the test of academic success $(\mathrm{U}=109.000 \mathrm{p}<.01)$. Examining Table 6, while the posttest mean rank score for the test of academic success of the students in the experimental group was 27.81 , the posttest mean rank score of the students in the control group was 16.45. Accordingly, the academic success of students in the experimental group with regard to simple electrical circuits was significantly greater than that of students in the control group. This result reveals that the STEM-based activity programme had a positive effect on the students' academic success in the subject of simple electrical circuits.

\section{Discussion and Conclusion}

The findings obtained for the first subproblem of the study reveal that when the mean scores of the students in the experimental and control groups are compared, no significant difference was found between mean scores of the groups for basic process skills, problem-solving skills or academic success. In other words, the levels of basic skills, problem-solving skills and academic success in students in the experimental and control groups forming the study group were equal.

The findings obtained for the second subproblem of the study reveal that there was a significant difference between the mean pretest and posttest scores of students in the experimental group for basic process skills and academic success. Based on this finding, it can be said that the STEM-based activities were effective in increasing the students' basic process skills and academic success. It was reported in a number of studies, such as those of Ceylan (2014); Olivarez (2012); Yıldırım and Altun (2015) and Yıldırım (2016) that STEM-based activities are effective in increasing students' academic success. Another finding of the study is that the STEM-based activities had a positive effect on students' basic process skills. This finding corresponds to the findings of a number of studies, such as those of Bozkurt (2014); Koç Şenol and Büyük (2015); Strong (2013); Sullivan (2008) and Yamak et al. (2014). On the other hand, it was determined that there was no difference between the mean pretest and posttest scores of students in the experimental group in the problem-solving skills scale. Based on this finding, it was concluded that the STEM-based activities had no effect on the students' problem-solving skills. This finding may 
be explained by the limited nature of the implementation process for the STEM-based activities carried out. In the literature, studies that support this finding can be found (Kim and Choi, 2012; Nağaç, 2018) whereas studies can also be found that conclude that STEM-based activities are effective in raising the level of problem-solving skills (Childress, 1996; Elliott et al., 2001; Ceylan, 2014).

The findings obtained for the third subproblem of the study reveal that the teaching method conducted with the control group also significantly increased the students' scores in basic process skills and academic success. However, when the students' mean pretest and posttest scores for basic process skills and academic success are examined, it is seen that the increase in scores between the pretest and posttest was greater in the experimental group than in the control group. In this case, it can be said the STEM-based activities were more effective in improving basic process skills and academic success than were the teaching methods suited to the 2013 science lesson teaching programme. The fact that the success of students in the control group with regard to simple electrical circuits was significantly greater in favour of the posttest may be explained by the fact that the science lesson teaching programme is based on a structured approach and that the activities in the programme are aimed towards this. On the other hand, it was determined that there was no difference between mean pretest and posttest scores of students in the control group for the problem-solving skills scale.

The findings obtained for the fourth subproblem of the study reveal that there was no difference between the mean posttest scores of the students in the experimental and control groups with regard to the basic skills scale or the problem-solving scale. However, it was concluded that the mean scores of students in the experimental group for the basic skills scale were higher than the mean scores of students in the control group. This finding may be explained by the fact that the STEM-based activities applied were limited to 12 lesson periods and that for students to acquire process skills, longer and more active periods are required. Following the three weeks of instruction carried out with the experimental and control groups, it was found that the posttest academic success scores of students in the experimental group were significantly higher than those of students in the control group. This finding corresponds to those in studies in the related literature (Cosentino, 2008; Riskowski et al., 2009; Olivarez, 2012; Ceylan, 2014; Tank, 2014; Ylldırım and Altun, 2015; Yıldırım, 2016). Therefore, it can be said that the STEM-based activity method produces more successful results for academic success in the subject of simple electrical circuits than the teaching method conducted according to the 2013 science lesson teaching programme.

\section{Recommendations}

In line with the findings obtained in the study, the following recommendations may be made for researchers studying the subject of STEM:

I. In the study, the subject of simple electrical circuits chosen in line with outcomes suitable for STEM-based activities was limited to a three-week period and to fourth-grade primary students. Since the period of this implementation was limited, an application over a longer period may reveal more beneficial results.

II. When preparing STEM-based activities, inclusion of ways of solving problems that students encounter in daily life or tools that they use in daily life may lead to more meaningful learning outcomes.

III. In future studies that are made, examining the effect of STEM applications on different variables (such as creative thinking skills and critical thinking skills) may contribute to the related literature.

IV. In this study, the STEM implementations that consist of the science, technology, engineering and mathematics disciplines were carried out in science lessons. In future studies that are conducted, STEM implementations can also be conducted in fields like mathematics, computers and technology.

\section{References}

Alpar, R., 2014. Practical statistics and validity-reliability with examples from sports, health and educational sciences. Ankara: Detay.

Aydoğdu, B. and F. Karakuş, 2015. Adaptation of basic skills scale for primary school students to Turkish. Mehmet Akif Ersoy University Faculty of Education Journal, 34(1): 105-131.

Baykul, Y. and C.O. Güzeller, 2014. Statistics for social sciences. Ankara: PegemA.

Bozkurt, E., 2014. The effect of engineering design-based science education on science decision-making skills, scientific process skills and perceptions of process. PhD Thesis, Gazi University, Institute of Educational Sciences, Ankara.

Büyüköztürk, Ş., 2014. Manual of data analysis for social sciences. Ankara: Pegem A.

Bybee, R.W., 2010. What is STEM education? Science, 329(5995): 996-996.

Cakmakçı, G., 2016. Stem stipulation to compete with the world. Available from http://www.hurriyet.com.tr/dunya-ile-rekabet-icin-stemsart-40087941.

Caycı, B. and R. Kılıç, 2017. The relationship between primary school students' academic achievement, science-mathematics attitudes and basic skill levels. International Journal of Eurasia Social Sciences, 8(28): 46-65.

Cepni, S., A. Ayas, A.R. Akdeniz, H. Özmen, N. Yiğit and H.Ş. Ayvacı, 2016. Teaching science and technology from theory to practice. Ankara: Pegema.

Cepni, S., A. Ayas, D. Johson and F. Turgut, 1997. Physics teaching. Ankara: Higher Education Council.

Ceylan, S., 2014. Science, technology, engineering and mathematics (Fetemm) approach to the preparation of ins tructional design for the acids and bases in the secondary school science course. Master Thesis, Uludag University, Institute of Educational Sciences, Bursa.

Childress, V.W., 1996. Does integration technology, science, and mathematics improve technological problem solving: A quasi-experiment. Journal of Technology Education, 8(1): 16-26.Available at: https://doi.org/10.21061/jte.v8i1.a.2.

Cokluk, Ö., G. Şekercioğlu and Ş. Büyüköztürk, 2016. Multivariate statistics spsss and lisrel applications for social sciences. Ankara: PegemA.

Corlu, M.S., 2012. A pathway to STEM education: Investigating pre-service mathematics and science teachers at Turkish universities in terms of their understanding of mathematics used in science. Doctoral dissertation, Texas AandM University, College Station.

Corlu, M.S., R.M. Capraro and M.M. Capraro, 2014. Introducing STEM education: Implications for educating our teachers for the age of innovation. Education and Science, 39(1): 74-85.

Cosentino, C., 2008. The impact of integrated programming on student attitude and achievement in grade 9 academic mathematics and science. Master's Thesis, Department of Graduate and Undergraduate Studies in Education, Brock University, Ontario.

Coşkun, M., 2000. Evaluation of teaching processes in geography course according to student views. Master Thesis, Gazi University, Institute of Social Sciences, Ankara.

Elliott, B., K. Oty, J. McArthur and B. Clark, 2001. The effect of an interdisciplinary algebra/science course on students' problem solving skills, critical thinking skills and attitudes towards Mathematics. International Journal of Mathematical Education in Science and Technology, 32(6): 811-816.Available at: https://doi.org/10.1080/00207390110053784.

Ge, X., 2001. Scaffolding students' problem-solving processes on an ill-structured task using question prompts and peer interactions. Doctor of Philosophy, The Pennsylvania State University, The Graduate School, College of Education. 
Karasar, N., 2015. Scientific research method. Ankara: Nobel.

Kim, G.-S. and S.Y. Choi, 2012. The effects of the creative problem solving ability and scientific attitude through the science-based STEAM program in the elementary gifted. Journal of Korean Elementary Science Education, 31 (2): $216-226$.

Koç Şenol, A. and U. Büyük, 2015. Robotic-assisted science and technology laboratory applications: Robolab. International Periodical For The Languages, 10(1): 213-236.

Lawshe, C.H., 1975. A quantitative approach to content validity. Personnel Psychology, 28(4): 563-575.Available at: https://doi.org/10.1111/j.1744-6570.1975.tb01393.x.

Ministry of Education, 2013. Science curriculum teaching program (elementary and middle schools 3, 4, 5, 6, 7 and 8). Ankara: MEB.

MoE, 2018. Science curriculum teaching program (elementary and middle schools 3, 4, 5, 6, 7 and 8). Ankara: MEB.

Nağaç, M., 2018. Investigation of the effect of science, technology, engineering and mathematics (Fetemm) education on the academic success and problem solving skills of the 6th grade science class material and heat unit. Master Thesis, Mustafa Kemal University, Institute of Science and Technology, Hatay.

Nuhoğlu, H., 2008. The development of an attitude scale for science and technology course. Elementary Education Online, 7(3): 627-639.

Olivarez, N., 2012. The impact of a STEM program on academic achievement of eighth grade students in a South Texas middle school. Doctoral Thesis, Texas A and M University.

Ostlund, K.L., 1992. Science process skills assesing hands-on student performance. Menlo Park, CA: Addison-Wesley.

Padilla, M., L. Cronin and M. Twiest, 1985. The development and validation of the test of basic process skills. Paper Presented at the Annual Meeting of the National Association for Research in Science Teaching, French Lick, IN.

Padilla, M.J., 1990. The science process skills. Research matters-To the science teacher, No. 9004. Reston, VA: National Association for Research in Science Teaching (NARST).

Riskowski, J.L., C.D. Todd, B. Wee, M. Dark and J. Harbor, 2009. Exploring the effectiveness of an in terdisciplinary water resources engineering module in an eighth grade science course. International Journal of Engineering Education, 25(1): $181-195$.

Rocard, M., P. Csermely, D. Jorde, D. Lenzen, H.W. Henriksson and V. Hemmo, 2007. Science education now: A new pedagogy for the future of Europe. European Commission Directorate General for Research Information and Communication. Available from http://ec.europa.eu/research/sciencesociety/document_library/pdf_06/report-rocard-onscience.

Senemoğlu, N., 2009. Developmental learning and teaching. Ankara: Pegem Academy.

Serin, O., 2004. The relationship between prospective teachers' problem solving skills and attitudes towards science. XIII National Educational Sciences Congress, Inonu University, Faculty of Education, Malatya.

Smith, J., 2000. The interdisciplinary curriculum: A literary review and a manual for administrators and teachers. Masters Dissertation, Texas Woman's University.

Strong, M.G., 2013. Developing elementary math and science process skills through engineering design instruction. Master's Thesis, Hofstra University, Hempstead, New York.

Sullivan, F.R., 2008. Robotics and science literacy: Thinking skills, science process skills and systems understanding. Journal of Research in Science Teaching: The Official Journal of the National Association for Research in Science Teaching, 45(3): 373-394.Available at: https://doi.org/10.1002/tea.20238.

Tan, Ş., 2011. Measurement and evaluation in teaching. Ankara: Pegema.

Tank, K.M., 2014. Examining the effects of integrated science, engineering, and nonfiction literature on student learning in elementary classrooms. Doctoral Dissertation, University of Minnesota, Mankato.

Yamak, H., N. Bulut and S. Dündar, 2014. The effect of fetemm activities on students' attitudes towards science with scientific process skills. Gefad, 34(2): 249-265.

Yıldırım, B., 2016. Science, technology, engineering mathematics (STEM) applications integrated in 7 th grade science course and the effects of full learning. Ph.D Thesis, Gazi University, Institute of Science and Technology, Ankara.

Yıldırım, B. and Y. Altun, 2015. Examination of the effects of STEM education and engineering applications on science course laboratory course. El-Cezeri Journal of Science and Engineering, 2(2): 28-40. 